\title{
Prevalence of Hepatitis B Serum Markers in Young Military Recruits in Greece: A Comparison Study between 2005 and 2019 Cohorts
}

\author{
Nikolaos Papadopoulos 1,*(D), Nikolaos Gkavogiannakis ${ }^{2}$, Stella Panagakou ${ }^{2}$, Gerasimos Papadatos ${ }^{2}$, \\ Evangelos Panagoulis ${ }^{2}$, Melanie Deutsch ${ }^{3}$, Konstantinos Liaskonis ${ }^{4}$ and Vasilios German ${ }^{5}$ \\ 1 1st Department of Internal Medicine, 417 Army Share Fund Hospital of Athens, 11521 Athens, Greece \\ 2 Medical Services, Supply and Transportation Corps Training Centre, 23100 Sparta, Greece; \\ nickagav@gmail.com (N.G.); stellapanagakou.sp@gmail.com (S.P.); Gerapapadatos@gmail.com (G.P.); \\ panagagelos@yahoo.gr (E.P.) \\ 3 2nd Department of Internal Medicine, Hippokration General Hospital of Athens, Medical School of National \\ \& Kapodistrian University of Athens, 11527 Athens, Greece; meladeut@gmail.com \\ 4 Department of Microbiology, 401 General Army Hospital of Athens, 11525 Athens, Greece; \\ liaskon@gmail.com \\ 5 2nd Department of Internal Medicine, 401 General Army Hospital of Athens, 11525 Athens, Greece; \\ vgerman@gmail.com \\ * Correspondence: nipapmed@gmail.com; Tel.: +30-693-260-4019
}

\section{check for}

updates

Citation: Papadopoulos, N.; Gkavogiannakis, N.; Panagakou, S.; Papadatos, G.; Panagoulis, E.; Deutsch, M.; Liaskonis, K.; German, V. Prevalence of Hepatitis B Serum Markers in Young Military Recruits in Greece: A Comparison Study between 2005 and 2019 Cohorts. Livers 2021, 1, 230-235. https:// doi.org/10.3390/livers1040018

Academic Editor: Eberhard Hildt

Received: 20 August 2021

Accepted: 1 November 2021

Published: 3 November 2021

Publisher's Note: MDPI stays neutral with regard to jurisdictional claims in published maps and institutional affiliations.

Copyright: (c) 2021 by the authors. Licensee MDPI, Basel, Switzerland. This article is an open access article distributed under the terms and conditions of the Creative Commons Attribution (CC BY) license (https:/ / creativecommons.org/licenses/by/ $4.0 /)$.
Abstract: Background: The prevalence of hepatitis B varies (HBV) among countries. Although an overall reduction has been described in Greece, data are limited. Methods: We reviewed the $\mathrm{HBs} \mathrm{Ag} / \mathrm{anti}-\mathrm{HBc}$ /anti-HBs seroprevalence among military recruits and compared data between 2005 and 2019. The study included 2001 (group 1) and 1629 (group 2) male recruits in 2019 and 2005, respectively. Age and descent were recorded. Results: The prevalence of $\mathrm{HBsAg}$, anti-HBc and anti-HBs positivity in group 1 vs. group 2 was estimated as: $0.2 \%, 1.3 \%$ and $67 \%$ vs. $0.4 \%, 1.6 \%$ and $62 \%$, respectively. Only anti-HBs positivity achieved a statistically significant difference between the two groups $(p=0.007)$. HBsAg and anti-HBc were more frequently positive in non-Greeks than in Greeks (9/237 (4\%) vs. 2/3393 (0.06\%), $p<0.001),(26 / 237(11 \%)$ vs. $26 / 3393(0.8 \%), p<0.001$ respectively), while anti-HBs was more frequently positive in Greeks than in non-Greeks (84/164 $(51 \%)$ vs. $1461 / 2213(66 \%), p<0.001)$. Conclusions: Our data suggest a further reduction in HBV prevalence in Greece about 20 years after the adoption of the National HBV Immunization Program, with Greek participants experiencing a more effective HBV Immunization Program than non-Greeks.

Keywords: hepatitis B virus (HBV); HBsAg; anti-HBc; anti-HBs; HBV immunization program

\section{Introduction}

More than two billion individuals have serologic evidence of hepatitis B virus (HBV) infection worldwide. Despite advances in antiviral therapy, a functional cure is rare. Although the prevalence of hepatitis B surface antigen (HBsAg) varies between European countries, the incidence of HBV has declined over the past ten years from 6.7 cases per 100,000 population in 1995 to 1.5 cases per 100,000 population in 2000 . This decline has been achieved mainly due to effective vaccination programs, blood donor control, predelivery evaluation of pregnant women, and passive-active immune-prophylaxis treatment of infants born from chronic HBV-infected mothers [1-6].

In the past, Greece has been considered part of a group of European countries with a high burden of HBV as the prevalence of HBsAg positivity was 2-7\%. However, although published general population data are limited, nowadays HBV prevalence in Greece seems to be around $2 \%$ [7-10]. Moreover, studies on military recruits exhibit a significant decline in HBsAg prevalence, from $4 \%$ in 1973 to $0.95 \%$ in 1999 and finally to $0.32 \%$ in 2005, 
mainly due to the modification of economic status and to the successful National HBV Immunization Program (Hellenic National Immunization Program for hepatitis B) that the Hellenic Government adopted in 1998 [11-14].

Migration to Greece from low- and middle-income countries in Eastern Europe with a high prevalence of HBV has increased since the 1990s. The relative contribution of first-generation migrants from intermediate and high-endemicity countries to the overall chronic hepatitis B (CHB) case burden in Greece has been estimated to be 29\% [6,15]. This study aimed to examine a possible shift in HBV epidemiology among military young adults between 2005 and 2019 and evaluate potential associations with epidemiological characteristics and $\mathrm{HBV}$ vaccination.

\section{Materials and Methods}

\subsection{Study Population}

The study sample consisted of 2001 volunteer male recruits (group 1), with a mean age of 21 (range: 18-39) years, who were referred to the Supply and Transportation Corps Training Centre of the Hellenic Army (Sparta, Greece) in 2019 and 1629 volunteer male recruits (group 2), with a mean age of 20 (range: 17-34) years, who were referred to the same Training Center back in 2005. The representativeness of group 2 has been previously presented in [13]. The study was performed according to the World Medical Association Declaration of Helsinki and approved by the Medical Directorate of the Hellenic Army General Staff.

\subsection{Laboratory Testing}

A venous blood specimen was taken from each subject under aseptic conditions. Sera were evaluated in the Microbiology Laboratory of 401 Army General Hospital of Athens within three hours to process $\mathrm{HBsAg}$, anti-HBs, and anti-HBc using commercially available enzyme immunoassays. Thus, $\mathrm{HBs} A g$ and anti-HBc markers were evaluated in all participants, while anti-HBs was assessed in 748/2001 (37.5\%) subjects of the first group and in all participants of the second.

All study participants were informed of the test results through personal interviews, while infected patients were referred to 401 Army General Hospital of Athens for further evaluation.

\subsection{Definitions}

The following different patterns were revealed: (1) HBsAg(+)/anti-HBc(+) as positive $\mathrm{HBsAg}$, (2) $\mathrm{HBsAg}(-) / \operatorname{anti}-\mathrm{HBc}(+)$ as indicative of past $\mathrm{HBV}$ exposure, (3) $\mathrm{HBsAg}(-) /$ antiHBc(-)/anti-HBs(+) with a titer $>10 \mathrm{IU} / \mathrm{mL}$ as indicative of immunity due to successful $\mathrm{HBV}$ vaccination, (4) $\mathrm{HBs} \mathrm{Ag}(-) / \operatorname{anti}-\mathrm{HBc}(+) / \operatorname{anti}-\mathrm{HBs}(+)$ as indicative of immunity due to natural $\mathrm{HBV}$ infection, and (5) $\mathrm{HBsAg}(-) /$ anti- $\mathrm{HBc}(-) /$ anti-HBs(-) as susceptible subjects [16].

\subsection{Data Collection}

Personal interviews were conducted to collect epidemiological data regarding age and geographic area of descent. Participants with no available data about age or descent were excluded in both groups. Immunization history with hepatitis B vaccine was obtained by checking the immunization certificate in 723/2001 (36\%) participants of group 1.

\subsection{Statistical Analysis}

All data were analyzed using the statistical package MedCalc (version 18.2). Statistical analysis was performed using the chi-squared test for comparisons of qualitative data between groups. A two-tailed $p$-value $<0.05$ was considered to be statistically significant. 


\section{Results}

All recruits in group 1 and group 2 were male, and their mean age was $21.73 \pm 2.72$ and $20.6 \pm 2$, respectively. Participants of group 2 were statistically significantly younger than those of group $1(p<0.001)$. Although most subjects were Greek, a statistically significant difference among the two groups was revealed ( $92.5 \%$ vs. $94.5 \%, p=0.008$ respectively). The vast majority of non-Greek subjects were second-generation migrants from Eastern Europe, mainly Albania. The baseline characteristics of both groups are shown in Table 1.

Table 1. Baseline characteristics of group 1 and group 2 participants.

\begin{tabular}{cccc}
\hline & Group 1 & Group 2 & $p$-Value \\
\hline N, number of participants & 2001 & 1629 & \\
Mean age \pm SD, years & $21.73 \pm 2.72$ & $20.6 \pm 2$ & $<0.001$ \\
Group of Age, n/N (\%) & & & \\
$17-19$ & $543 / 2001(27)$ & $731 / 1629(45)$ & \\
$20-22$ & $771 / 2001(38.5)$ & $605 / 1629(37)$ & $<0.001$ \\
$\geq 23$ & $687 / 2001(34.5)$ & $293 / 1629(18)$ & \\
Greeks, n/N (\%) & $1852 / 2001(92.5)$ & $1541 / 1629(94.5)$ & 0.008 \\
\hline
\end{tabular}

The number of positive HBsAg patients was: 5/2001 (0.2\%) in group 1 and 6/1629 $(0.4 \%)$ in group $2(p=0.364)$. Subjects with past HBV exposure were: $26 / 2001(1.3 \%)$ in group 1 and $26 / 1629(1.6 \%)$ in group $2(p=0.271)$.

Subjects with indicative immunity due to successful HBV vaccination were: 502/748 $(67 \%)$ in group 1 and $1006 / 1629(62 \%)$ in group $2(p=0.007)$. To evaluate the long-term immune status after HBV immunization, we further analyzed 723 participants of group 1 who were all vaccinated in childhood against HBV according to their immunization schedule certificate. Finally, 507/723 (70\%) of these previously vaccinated participants had protective anti-HBs titers.

Subjects with immunity due to natural HBV infection were: $19 / 748(2.5 \%)$ in group 1 and $18 / 1629(1.1 \%)$ in group $2(p=0.009)$. Susceptible subjects were: $220 / 748(29.5 \%)$ in group 1 and $597 / 1629(36.5 \%)$ in group $2(p<0.001)$. The results of the above-mentioned serologic analysis are shown in Table 2.

Table 2. HBV serologic markers among group 1 and group 2 participants.

\begin{tabular}{cccc}
\hline & Group 1 * & Group 2 & $p$-Value \\
\hline HBsAg(+)/anti-HBc(+), n/N (\%) & $5 / 2001(0.2)$ & $6 / 1629(0.4)$ & 0.364 \\
\hline HBsAg(-)/anti-HBc(+), n/N (\%) & $26 / 2001(1.3)$ & $26 / 1629(1.6)$ & 0.271 \\
\hline HBsAg(-)/antiHBc(-)/anti-HBs(+), n/N (\%) & $502 / 748(67)$ & $1006 / 1629(62)$ & 0.007 \\
\hline HBsAg(-)/anti-HBc(+)/anti-HBs(+), n/N (\%) & $19 / 748(2.5)$ & $18 / 1629(1.1)$ & 0.009 \\
\hline HBsAg(-)/anti-HBc(-)/anti-HBs $(-), \mathrm{n} / \mathrm{N}(\%)$ & $220 / 748(29.5)$ & $597 / 1629(36.5)$ & $<0.001$ \\
\hline${ }^{*}$ Anti-HBs was evaluated in 748/2001 (37.5\%) of the group 1.
\end{tabular}

Among all participants, HBsAg and anti-HBc were more frequently positive in nonGreeks than in Greeks $(9 / 237(4 \%)$ vs. $2 / 3393(0.06 \%), p<0.001),(26 / 237(11 \%)$ vs. $26 / 3393$ $(0.8 \%), p<0.001$, respectively), while anti-HBs was more frequently positive in Greeks than in non-Greeks $(84 / 164(51 \%)$ vs. $1461 / 2213(66 \%), p<0.001)$. To exclude the possibility that this finding did not reflect the statistically significant difference in descent between the two groups, we performed the same analysis in each group separately. Nevertheless, even in each group analysis, $\mathrm{HBsAg}$ and anti-HBc were more frequently positive in non-Greeks than in Greeks $(4 / 149(2.5 \%)$ vs. $1 / 1852(0.05 \%), p<0.001),(17 / 149(11.5 \%)$ vs. $9 / 1852$ $(0.5 \%), p<0.001)$ and $(5 / 88(5.5 \%)$ vs. $1 / 1541(0.06 \%), p<0.001),(9 / 88(10.2 \%)$ vs. $17 / 1541$ $(1.1 \%), p<0.001)$ in group 1 and group 2 , respectively, while anti-HBs was more frequently 
positive in Greeks than in non-Greeks (41/76 (54\%) vs. $480 / 672(71.5), p=0.002)$ and $(43 / 88$ $(49 \%)$ vs. $981 / 1541(63.5 \%), p=0.004)$ in group 1 and group 2 , respectively (Table 3$)$.

Table 3. Factors associated with $\mathrm{HBsAg}$, anti-HBc and anti-HBs positivity.

\begin{tabular}{|c|c|c|c|c|c|c|c|}
\hline Descent & $\begin{array}{c}\text { HBsAg } \\
\text { Positive, n/N } \\
(\%)\end{array}$ & $\begin{array}{c}\text { HBsAg } \\
\text { Negative, } \mathrm{n} / \mathrm{N} \\
(\%)\end{array}$ & $\begin{array}{c}\text { anti-HBc } \\
\text { Positive, } \mathrm{n} / \mathrm{N} \\
(\%)\end{array}$ & $\begin{array}{c}\text { anti-HBc } \\
\text { Negative, n/N (\%) }\end{array}$ & $\begin{array}{c}\text { anti-HBs } \\
\text { Positive, n/N } \\
(\%)\end{array}$ & $\begin{array}{c}\text { anti-HBs } \\
\text { Negative, } \mathrm{n} / \mathrm{N} \\
(\%)\end{array}$ & $p$-Value \\
\hline \multicolumn{8}{|l|}{ Both Groups } \\
\hline non-Greeks & 9/237 (4) & $228 / 237$ (96) & $26 / 237(11)$ & 211/237 (89) & $84 / 164$ (51) & $80164 /(49)$ & \multirow{2}{*}{$<0.001$} \\
\hline Greeks & $2 / 3393(0.06)$ & $3391 / 3393$ (99.94) & $26 / 3393(0.8)$ & $3367 / 3393(99.2)$ & $1461 / 2213(66)$ & $752 / 2213(34)$ & \\
\hline \multicolumn{8}{|l|}{ Group $1^{*}$} \\
\hline non-Greeks & $4 / 149(2.5)$ & $145 / 149(97.5)$ & $17 / 149$ (11.5) & $132 / 149(88.5)$ & $41 / 76(54)$ & $35 / 76(46)$ & \multirow{2}{*}{$<0.001$} \\
\hline Greeks & $1 / 1852(0.05)$ & $1851 / 1852$ (99.95) & 9/1852 (0.5) & $1843 / 1852(99.5)$ & $480 / 672(71.5)$ & $192 / 672(28.5)$ & \\
\hline \multicolumn{8}{|l|}{ Group 2} \\
\hline non-Greeks & $5 / 88(5.5)$ & $83 / 88$ (94.5) & 9/88 (10.2) & $79 / 88(89.8)$ & $43 / 88(49)$ & $45 / 88(51)$ & \multirow{2}{*}{$<0.05$} \\
\hline Greeks & $1 / 1541(0.06)$ & 1540/1541 (99.94) & $17 / 1541(1.1)$ & $1524 / 1541(98.9)$ & $981 / 1541(63.5)$ & $560 / 1541(36.5)$ & \\
\hline
\end{tabular}

* Anti-HBs was evaluated in 748/2001 (37.5\%) of the group 1.

Age, either as a quantitative or as a qualitative variable, was not associated as a prognostic factor of any HBV serology marker in both groups of participants.

\section{Discussion}

The primary scope of our study was to determine the prevalence of seropositivity for HBsAg during the last 14 years. In 2005, HBsAg seroprevalence among military recruits was estimated at $0.4 \%$ [13]. Furthermore, we documented a further reduction as we have an estimated HBsAg seropositivity prevalence of $0.2 \%$ in 2019. Although this finding is not statistically significantly different among the two groups of participants, it confirms a continuing trend in the reduction in HBsAg positivity prevalence in Greece about 20 years after the adoption of universal immunization against HBV in the Greek population [11]. In 1971, HBsAg positive prevalence in military recruits was estimated as $4.9 \%$, while in 1998, in a similar military population it was $0.95 \%$ [11,17]. General population published data are limited in Greece, whereas the best-studied group is that of blood donors. In 1999, a large population study of blood donors on the island of Crete for five consecutive years revealed that the mean prevalence of HBsAg was $0.4 \%$ [8]. Only one published study concerning the general population has been conducted in the region of South-Western Greece in 2002 and it revealed a seroprevalence for HBsAg positivity of 2.1\% [7]. Although our study's results cannot be extrapolated to women or high-risk populations such as people who inject drugs (PWIDs), sex workers, multi-transfused patients, or patients in hemodialysis, it included a significant number of second-generation migrants from high-prevalence HBsAg positive areas of Eastern Europe [10,18]. Although non-Greek participants were more likely to be HBsAg and/or anti-HBc positive than Greeks, they did not seem to significantly modify the epidemiological data, as the prevalence of HBsAg positivity in group 1 was only $0.2 \%$. Thus, we believe that our results, even with the limitations of the selected included population, are consistent with an overall reduction in HBV prevalence in Greece [19].

The key to this reduction in HBsAg positivity seems to be the effective Hellenic National Immunization Program for hepatitis B, which was adopted in 1998 and included all infants and all 12-year-old children at that time. As the mean age of participants in group 1 was $21.73 \pm 2.72$ years old, most of them were born around 1998. Thus, most of them should have been vaccinated against HBV. Indeed, we found that $67 \%$ of these subjects had an adequate titer of anti-HBs. Moreover, among a sub-group of 723 participants with a certificate proving vaccination, 507 of them $(70 \%)$ had protective anti-HBs levels, which are the highest mentioned in the literature [20-23]. Interestingly, we found that group 2, aged $20.6 \pm 2$ years old, who were born around the middle of the 1980s, also achieved an adequate anti-HBs titer of $62 \%$, which is consistent with the successful immunization 
program of all 12-year-old children in 1998 mentioned above. However, a statistically significant difference in protective anti-HBs titer favors group 1 participants, which is compatible with a more effective vaccination program in those who were born in Greece in the late 1990s. This finding underlines the significant role of migrants in the epidemiology of HBV infection as $>45 \%$ of non-Greek participants in both groups were more likely to be susceptible to HBV infection due to non-vaccination.

\section{Conclusions}

In conclusion, our data suggest a further reduction in HBV prevalence in Greece. Moreover, the Hellenic National Immunization Program for hepatitis B seems to have been largely successful in reducing the prevalence of hepatitis B infection and it has increased the immunity levels in the population. However, the migration of people from countries of high endemicity may contribute to a modification of the epidemiological data. Since the most effective means of prevention against $\mathrm{HBV}$ is vaccination, health care professionals should raise awareness about hepatitis $B$ and encourage adherence to guidelines according to the National Immunization Program for hepatitis B [24].

Author Contributions: Authors contributed equally to this manuscript. N.P. wrote, edited, and conceived the manuscript. N.G. wrote and conceived the manuscript. S.P. wrote, and conceived the manuscript. G.P. wrote, and conceived the manuscript. E.P. wrote, and conceived the manuscript. M.D. wrote, edited, and conceived the manuscript. K.L. wrote, and conceived the manuscript. V.G. wrote, edited, and conceived the manuscript. All authors have read and agreed to the published version of the manuscript.

Funding: This research received no external funding.

Institutional Review Board Statement: The study was conducted according to the guidelines of the Declaration of Helsinki, and approved by the Institutional Review Board of 401 General Army Hospital of Athens ( $\Phi .040 / 15 / 30746 / \Sigma .7049 / 11-11-2019)$.

Informed Consent Statement: Informed consent was obtained from all subjects involved in the study.

Data Availability Statement: The data presented in this study are available on request from the corresponding author.

Conflicts of Interest: The authors declare no conflict of interest.

\section{References}

1. Ott, J.J.; Stevens, G.A.; Groeger, J.; Wiersma, S.T. Global epidemiology of hepatitis B virus infection: New estimates of age-specific HBsAg seroprevalence and endemicity. Vaccine 2012, 30, 2212-2219. [CrossRef]

2. Schweitzer, A.; Horn, J.; Mikolajczyk, R.T.; Krause, G.; Ott, J.J. Estimations of worldwide prevalence of chronic hepatitis B virus infection: A systematic review of data published between 1965 and 2013. Lancet 2015, 386, 1546-1555. [CrossRef]

3. Zhang, Q.; Qi, W.; Wang, X.; Zhang, Y.; Xu, Y.; Qin, S.; Zhao, P.; Guo, H.; Jiao, J.; Zhou, C.; et al. Epidemiology of Hepatitis B and Hepatitis C Infections and Benefits of Programs for Hepatitis Prevention in Northeastern China: A Cross-Sectional Study. Clin. Infect. Dis. 2015, 62, 305-312. [CrossRef]

4. Pantazis, K.D.; Elefsiniotis, I.S.; Brokalaki, H. New Data concerning the Epidemiology of Hepatitis B Virus Infection in Greece. Gastroenterol. Res. Pract. 2008, 2008, 580341. [CrossRef]

5. Rantala, M.; van de Laar, M.J. Surveillance and epidemiology of hepatitis B and C in Europe-A review. Eur. Surveill. 2008, 13, 18880. [CrossRef]

6. Hatzakis, A.; Wait, S.; Bruix, J.; Buti, M.; Carballo, M.; Cavaleri, M.; Colombo, M.; Delarocque-Astagneau, E.; Dusheiko, G.; Esmat, G.; et al. The state of hepatitis B and C in Europe: Report from the hepatitis B and C summit conference. J. Viral. Hepat. 2011, 18, 1-16. [CrossRef]

7. Gogos, C.; Fouka, K.; Nikiforidis, G.; Avgeridis, K.; Sakellaropoulos, G.; Bassaris, H.; Maniatis, A.; Skoutelis, A. Prevalence of hepatitis B and C virus infection in the general population and selected groups in South-Western Greece. Eur. J. Epidemiol. 2002, 18, 551-557. [CrossRef] [PubMed]

8. Koulentaki, M.; Spanoudakis, S.; Kantidaki, E.; Drandakis, P.; Tzagarakis, N.; Biziagos, E.; Moschandrea, J.; Kouroumalis, E.A. Prevalence of hepatitis B and C markers in volunteer blood donors in Crete. A 5-year study. J. Viral Hepat. 1999, 6, 243-248. [CrossRef] [PubMed]

9. Kyriakis, K.P.; Foudoulaki, L.E.; Papoulia, E.I.; Sofroniadou, K.E. Seroprevalence of hepatitis B surface antigen (HBsAg) among first-time and sporadic blood donors in Greece: 1991-1996. Transfus. Med. 2000, 10, 175-180. [CrossRef] 
10. Zervou, E.K.; Dalekos, G.N.; Boumba, D.S.; Tsianos, E.V. Value of anti-HBc screening of blood donors for prevention of HBV infec-tion: Results of a 3-year prospective study in Northwestern Greece. Transfusion 2001, 41, 652-658. [CrossRef]

11. Papaevangelou, G. Hepatitis B immunization programme: Lessons learnt in Greece. Vaccine 1998, 16 (Suppl. 1), S45-S47. [CrossRef]

12. Stamouli, M.; Gizaris, V.; Totos, G.; Papaevangelou, G. Decline of hepatitis B infection in Greece. Eur. J. Epidemiol. 1999, 15, 447-449. [CrossRef] [PubMed]

13. German, V.; Giannakos, G.; Kopterides, P.; Liaskonis, K.; Falagas, M.E. Serologic indices of hepatitis B virus infection in military recruits in Greece (2004-2005). BMC Infect. Dis. 2006, 6, 163. [CrossRef]

14. Poland, G.A.; Jacobson, R.M. Prevention of Hepatitis B with the Hepatitis B Vaccine. N. Engl. J. Med. 2004, 351, 2832-2838. [CrossRef] [PubMed]

15. European Centre for Disease Prevention and Control. Epidemiological Assessment of Hepatitis B and C among Migrants in the EU/EEA; ECDC: Stockholm, Sweden, 2016.

16. Yuen, M.F.; Chen, D.S.; Dusheiko, G.M.; Janssen, H.L.; Lau, D.T.; Locarnini, S.A.; Peters, M.G.; Lai, C.L. Hepatitis B virus infection. Nat. Rev. Dis. Primers 2018, 4, 18035. [CrossRef] [PubMed]

17. Vissoulis, H.; Hadziyannis, S.; Papaevangelou, G.; Afroudakis, A.; Giannopoulos, C.; Gioustosi, A.; Merikas, G.L. Geographical distribution of hepatitis-associated antigen carriers in Greece. Nosokomiaka Chronika 1972, 34, 5-10. (In Greek)

18. Dalekos, G.N.; Zervou, E.; Karabini, F.; Tsianos, E.V. Prevalence of viral markers among refugees from southern Albania: In-creased incidence of infection with hepatitis A, B and D viruses. Eur. J. Gastroenterol. Hepatol. 1995, 7, 553-558.

19. Papatheodoridis, G.; Sypsa, V.; Kantzanou, M.; Nikolakopoulos, I.; Hatzakis, A. Estimating the treatment cascade of chronic hepa-titis B and C in Greece using a telephone survey. J. Viral. Hepat. 2015, 22, 409-415. [CrossRef]

20. Jack, A.D.; Hall, A.J.; Maine, N.; Mendy, M.; Whittle, H.C. What Level of Hepatitis B Antibody Is Protective? J. Infect. Dis. 1999, 179, 489-492. [CrossRef]

21. Hammitt, L.L.; Hennessy, T.W.; Fiore, A.E.; Zanis, C.; Hummel, K.B.; Dunaway, E.; Bulkow, L.; McMahon, B.J. Hepatitis B immunity in children vaccinat-ed with recombinant hepatitis B vaccine beginning at birth: A follow-up study at 15 years. Vaccine 2007, 25, 6958-6964. [CrossRef] [PubMed]

22. Lin, A.W.-C.; Wong, K.-H. Long-term protection of neonatal hepatitis B vaccination in a 30-year cohort in Hong Kong. J. Hepatol. 2013, 59, 1363-1364. [CrossRef]

23. Gara, N.; Abdalla, A.; Rivera, E.; Zhao, X.; Werner, J.; Liang, T.J.; Hoofnagle, J.H.; Rehermann, B.; Ghany, M.G. Durability of Antibody Response Against Hepatitis B Virus in Healthcare Workers Vaccinated as Adults. Clin. Infect. Dis. 2015, 60, 505-513. [CrossRef] [PubMed]

24. Expert Panel on Effective Ways of Investing in Health (EXPH). Preliminary Report on Vaccination Programmes and Health Systems in Europe; Publications Office of the European Union: Luxemburg, 2018. Available online: https://ec.europa.eu/health/expert_ panel/sites/expertpanel/files/020_vaccinationpgms_en.pdf (accessed on 2 September 2021). 